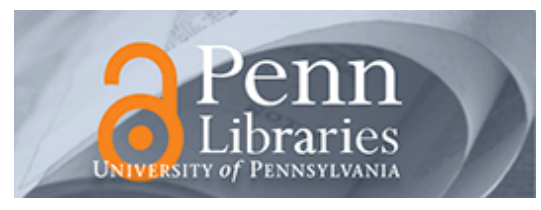

University of Pennsylvania

ScholarlyCommons

Marketing Papers

Wharton Faculty Research

4-2002

\title{
Undoing the Effects of Seizing and Freezing: Decreasing Defensive Processing of Personally Relevant Messages
}

Lauren G. Block

Patti Williams

University of Pennsylvania

Follow this and additional works at: https://repository.upenn.edu/marketing_papers

Part of the Applied Behavior Analysis Commons, Cognition and Perception Commons, Cognitive Psychology Commons, Community Psychology Commons, Marketing Commons, and the Social Psychology Commons

\section{Recommended Citation}

Block, L. G., \& Williams, P. (2002). Undoing the Effects of Seizing and Freezing: Decreasing Defensive Processing of Personally Relevant Messages. Journal of Applied Social Psychology, 32 (4), 803-830. http://dx.doi.org/10.1111/j.1559-1816.2002.tb00243.x

This paper is posted at ScholarlyCommons. https://repository.upenn.edu/marketing_papers/260

For more information, please contact repository@pobox.upenn.edu. 


\title{
Undoing the Effects of Seizing and Freezing: Decreasing Defensive Processing of Personally Relevant Messages
}

\author{
Abstract \\ Health messages are directed at those who are at risk of incurring adverse consequences. However, \\ previous experiments have found that people process personally relevant health messages in a biased, \\ defensive manner. We examine the role of elaboration as a mechanism to encourage less biased \\ processing of personally relevant health appeals. Results demonstrate that high-relevance consumers \\ freeze on the threatening information, leading to lower change appraisal (perceived severity, self-efficacy, \\ and response efficacy) and decreased message persuasion. For these individuals, renewed elaboration \\ on the consequences of caffeine (Experiment 1) and olestra (Experiment 2) consumption reduces \\ defensive processing. This elaboration "unfreezes" message processing, leading to greater change \\ appraisal and increased persuasion. These experiments provide guidelines for practitioners to design \\ more effective messages.

\section{Disciplines} \\ Applied Behavior Analysis | Business | Cognition and Perception | Cognitive Psychology | Community \\ Psychology | Marketing | Social Psychology
}




\title{
UNDOING THE EFFECTS OF SEIZING AND FREEZING:
}

\section{DECREASING DEFENSIVE PROCESSING OF}

\section{PERSONALLY RELEVANT MESSAGES}

\author{
Lauren G. Block \\ Zicklin School of Business, Baruch College \\ Patti Williams \\ The Wharton School, University of Pennsylvania
}

October 2000

Running Head: Decreasing Defensive Processing of Personally Relevant Messages 


\begin{abstract}
Health messages advocating behavioral change are directed at those who are at risk of incurring adverse consequences. However, previous studies have found that people process personally relevant health messages in a biased, defensive manner, leading to decreased persuasion. This paper examines the role of elaboration as a mechanism to encourage less biased processing of personally relevant health appeals for consumers of caffeine (Study 1) and olestra (Study 2). Results of two studies demonstrate that high-relevance consumers defensively process by freezing on the threatening information, which leads to lower change appraisal (perceived severity, self-efficacy and response efficacy) and decreased message persuasion. For these individuals, renewed elaboration on the consequences of caffeine (Study 1) and olestra (Study 2) consumption can reduce defensive processing. This elaboration "unfreezes" message processing, which leads to greater change appraisal and increased message persuasion. These studies provide practical guidelines for practitioners to design more effective health-related ads.
\end{abstract}




\section{UNDOING THE EFFECTS OF SEIZING AND FREEZING: DECREASING DEFENSIVE}

\section{PROCESSING OF PERSONALLY RELEVANT MESSAGES}

It is widely accepted that people process a message more objectively and extensively when the message is personally relevant (Petty \& Cacioppo, 1986). Numerous studies show that when the topic is personally relevant, persuasion is enhanced for messages containing strong arguments and decreased for messages containing weak arguments (see Eagly \& Chaiken, 1993 for a review). However, a growing body of literature suggests that under some circumstances, personal relevance can inhibit objective processing, instead leading to biased, defensive processing (Kunda, 1990; Liberman \& Chaiken, 1992). For example, Kunda $(1987,1990)$ suggests that when people are motivated to arrive at particular conclusions, as may be the case when the topic is personally relevant, message processing may be biased in support of that desired conclusion. Similarly, Liberman and Chaiken (1992) suggest that personal relevance leads to biased processing for messages that are threatening, like health messages and fear appeals. Common wisdom supports the theorizing that personally relevant threatening messages may lead to defensive and biased processing. Think of smokers ignoring the Surgeon General's warnings on cigarette cartons, or drug abusers denying the information in anti-drug advertisements.

The main audience of health messages is the at-risk population, but these people are also the most difficult to persuade because they often defensively process the information. It is thus important to better understand the defensive process and how it might be reduced, in order to increase persuasion and compliance among those most at-risk. The current research examines defensive message processing and persuasion for low versus high-relevant consumers of caffeine (study 1) and olestra (study 2). The figure illustrates the proposed conceptual framework that illustrates how increased elaboration on the consequences of engaging in the at-risk behavior increases message persuasion among high-relevance consumers. 
$\overline{\text { Figure about here }}$

The theory provides practical guidelines for practitioners to design more effective healthrelated ads. In addition, this research contributes to the social psychology and health persuasion literatures by a) proposing a theory that allows for different processing strategies within the group of high-relevance consumers, as well as between high- and low-relevance consumers; b) formally incorporating the role of elaboration in altering perceptions of severity and efficacy; c) introducing change appraisal (combination of perceived severity, self-efficacy and response efficacy), and specifying it as the process by which elaboration influences message persuasion; and, d) identifying elaboration on consequences of engaging in risky behaviors rather than elaboration on recommendations for reduction in such behaviors as the driving force behind message persuasion for high-relevance consumers.

\section{Defensive Processing of Threatening Messages}

When presented with a message that threatens one's sense of physical or emotional security, an individual might engage in defensive mechanisms that function to reduce the threat (Leventhal, 1970). People most at-risk-those for whom the message is most personally relevant because they are most likely to engage in the targeted set of risky-behaviors—are typically the ones most likely to employ defensive techniques like message avoidance (Donohew, Lorch \& Palmgreen, 1991) or denial of susceptibility ("I am the exception to the rule," Stuteville, 1970). Several recent studies suggest that increased personal relevance not only affects people's judgments of personal association to the message (resulting in avoidance or denial of susceptibility), but also the type of processing used (e.g., systematic vs. heuristic processing) and subsequent evaluation of message information (Kunda, 1987; Jemmott, Ditto and Croyle, 1986; Liberman \& Chaiken, 1992). 
Kunda (1987) examined whether people evaluate scientific evidence in a self-serving manner and found that heavy caffeine drinkers doubt the evidence regarding the hazards of caffeine consumption more than people who consume less caffeine do. Interestingly, heavy caffeine consumers agreed that they were more likely to develop the disease (fibrocystic breast disease) than low caffeine consumers. Thus, it appears that despite feeling more susceptible to the disease, high-relevance subjects processed the message in a biased, self-serving manner. Jemmott, Ditto and Croyle (1986) similarly found indication of biased processing among highrelevance subjects who tended to derogate the validity of a test to detect an enzyme deficiency more than low-relevance subjects did.

While both Kunda (1987) and Jemmott et al. (1986) provide evidence of biased judgment, neither of these studies addresses the processes leading to biased judgments of message persuasion. Are high-relevance subjects not attending to the threatening message as much as lowrelevance subjects, or are they instead engaging in a more active defensive strategy, like generating counterarguments? To address this question, Liberman and Chaiken (1992) designed a study to examine the mechanisms that mediate biased judgments of health messages. Returning to Kunda's original context, they investigated high versus low-relevance subjects' processing of a message on caffeine consumption and fibrocystic disease. Consistent with previous studies, they find that high-relevance subjects believed less strongly in the link between caffeine and fibrocystic disease than did low-relevance subjects. However, the high-relevance subjects' biased judgments were not mediated by defensive inattention, as indicated by greater self-reported effort for the high-relevance subjects, but rather by what the authors call "defensive systematic processing" of the message. Compared to low-relevance subjects, high-relevance individuals are more critical of portions of the persuasive messages linking their behavior with a threat (e.g., caffeine consumption and fibrocystic disease) and less critical of the portions of the message that shed doubt on that link (Liberman and Chaiken 1992). 
Liberman and Chaiken's documentation of defensive systematic processing is intriguing because it suggests that high-relevance subjects are indeed processing health appeals systematically, but with a bias toward information that helps them maintain their status quo: i.e., maintain their current maladaptive behavior. Thus, a mechanism that reduces this bias might lead to more favorable judgments and compliance with recommended behavior. Two recent studies in the fear appeal and information processing literatures implicate increased message elaboration as the mechanism that could reduce defensive systematic processing. The relation between message elaboration and defensive systematic processing is discussed below.

\section{Elaboration and the Reduction of Defensive Systematic Processing}

Kruglanski and Webster's 1996 paper on extent of processing provides insight into how high-relevance people might process information on the consequences of unhealthy behavior, leading them to focus on the parts of the message that safeguard, or enable them to maintain, their current behavior. In their research, the authors examine how people's desire for a firm answer and aversion toward ambiguity (termed need for closure) affects the way information is processed when rendering judgments. Specifically, there exists a tendency for individuals to 1) preserve past knowledge and 2) safeguard future knowledge (i.e., limit learning new information that challenges the beliefs they already hold). This translates into a variety of processing biases, one of which is to "seize" on information supporting past knowledge, and "freeze" on it, becoming impervious to subsequent information and curtailing message ela boration (Kruglanski \& Webster, 1996). This is also consistent with Liberman and Chaiken's (1992) data; their high-relevance subjects seized the information that would serve to preserve prior behavior, and resisted or refuted other information.

The notion of seizing and freezing is also consistent with a recent study on health-related fear appeals suggesting that insufficient elaboration on the consequences of engaging in at-risk behaviors can inhibit message persuasion. Health-related appeals typically provide information 
regarding both the adverse consequences of engaging in destructive behavior and recommendations for modifying the behavior to avoid the negative consequences (Hovland et al., 1953). Keller and Block (1996) determined that elaboration on the consequences of smoking mediates the persuasiveness of anti-smoking fear appeals. In a series of mediation analyses, Keller and Block (1996) tested the relationships among elaboration on the consequences of smoking, elaboration on the recommendations to stop smoking and message persuasiveness. They found that across varying levels of fear, 1) elaboration on the consequences of smoking drives elaboration on the recommendations to stop smoking, and 2) this in turn determines persuasion. The Keller and Block (1996) and Kruglanski and Webster (1996) papers together suggest a way to reduce defensive systematic processing. Specifically, seizing and freezing reduces message elaboration. By implication, encouraging or forcing renewed elaboration on the message may "undo" the effects of seizing and freezing. For health-related or threatening messages in particular, elaboration on the consequences of engaging in the at-risk behavior is critical for message persuasion.

However, while these papers provide a promising start for understanding the effects of elaboration on defensive processing, they are silent on the process by which elaboration increases the persuasiveness of health-related appeals. Keller and Block suggest two thought categories, elaboration on the consequences ("problem elaboration") and elaboration on the recommendations (“solution elaboration”) as the process leading to message persuasion. However, given the objectives of their study, they only varied problem elaboration and did not directly test the effect of varying levels of solution elaboration. Thus, these thought categories may be providing only a limited explanation of the process underlying message persuasion. Additionally, a vast literature on health prevention suggests several important variables that motivate protective behavior: perceived severity, perceived efficacy and perceived vulnerability. The relationship between elaboration and these health prevention predictor variables needs to be clarified. Thus, the important theoretical question of how elaboration on the consequences of 
engaging in at-risk behavior motivates health persuasion remains unanswered. We propose that elaboration on the consequences of a health-related message "undoes" the defensive processing of seizing and freezing for highly relevant individuals. Furthermore, we suggest that such elaboration arouses change appraisal (the appraisal of one's need to change one's behavior), indexed by increased levels of perceived severity, response efficacy and self-efficacy. Change appraisal in turn determines intended compliance.

\section{Elaboration Leads to Change Appraisal}

Protection Motivation Theory (PMT, Rogers, 1975, 1983) is an expectancy-value theory of behavioral change that explicitly incorporates the role of health-related messages. According to PMT, viewing a health-related message provides the impetus for an individual to assess the severity of an event, probability of the event's occurrence, belief in the efficacy of the recommendations provided in the message, and belief that one can successfully carry out the recommendations. Together, perceived severity and susceptibility (threat appraisal), and response efficacy and self-efficacy (coping appraisal) combine to elicit "protection motivation" which in turn provides the incentive to seek a healthier behavior (Rogers, 1975, 1983).

PMT assumes that the communication variables (e.g., perceived severity) are assessed independently of one another, and that they will be roughly proportional to the strength of the corresponding message variable. It is the consequences presented in the message that give rise to perceptions of severity. Likewise, it is the recommendations presented in the message that give rise to perceptions of efficacy. This basic premise of PMT provides the clues to understanding the process by which elaboration increases the persuasiveness of a health-related message.

As illustrated conceptually in the figure, the current research outlines a process of message persuasion consistent with both PMT and the notion of frozen processing. Highrelevance people tend to defensively process by freezing on information about the consequences of engaging in at-risk behavior. By doing so, they can maintain their perception that the 
consequences of continuing their behavior are of low severity. Moreover, since they freeze at this point in the message, their processing of the recommendations will be limited, giving rise to lower perceptions of response and self-efficacy. By contrast, high-relevance people who are forced to elaborate on the consequences will have greater perceived severity. Additionally, unfreezing on the consequences will enable greater processing of the recommendations, giving rise to greater perceptions of efficacy. In the present research, belief about the severity of the consequences and efficacy of the recommendations is called change appraisal. For highrelevance people, increased change appraisal leads to greater intentions to comply with the message. Perceived vulnerability is not part of change appraisal. Recent research suggests that only when a person feels vulnerable to the threat will a subsequent change in health-related attitudes or behaviors occur (Prochaska, Norcross \& DiClemente, 1994). In other words, perceptions of vulnerability precede one's appraisal of their need to change their behavior. By definition, high-relevance individuals are more vulnerable to the threat than low-relevance individuals. For low-relevance people who are less vulnerable to the threat, there should be no change in change appraisal or persuasion.

Change appraisal is a new construct that is conceptually related to, although distinct from protection motivation. The critical distinction is in treating perceived vulnerability as an antecedent to an appraisal process. This allows for the possibility that people who are more vulnerable to a threat will process messages differently than people who are less vulnerable. Conceptually, this is similar to the stage theories in suggesting that people who differ in perceived vulnerability have different processing biases and strategies (e.g., Weinstein, Lyon, Sandman and Cuite 1998; more detail on stage theory can be found in the Discussion). Since change appraisal does not strictly conform to Rogers' definition of threat appraisal, coping appraisal or protection motivation, it is appropriate to designate it with a unique identity. However, change appraisal is conceptually related to PMT in its treatment of perceived severity, response and self-efficacy; we 
therefore use Rogers' specifications for the combinatorial rule for these three factors. ${ }^{1}$ The hypothesized process of message elaboration and change appraisal is formally stated below:

H1: High-relevance subjects who do not elaborate on the consequences freeze on threatening message information. High-relevance subjects who do elaborate on the consequences "unfreeze" and continue processing the threatening information.

H2: Change appraisal for high-relevance subjects who elaborate on the consequences will be greater than that of high-relevance subjects who do not elaborate on the consequences. Change appraisal for low-relevance subjects who elaborate on the consequences will not differ from that of low-relevance subjects who do not elaborate on the consequences.

H3: Message persuasion for high-relevance subjects who elaborate on the consequences will be greater than that of high-relevance subjects who do not elaborate on the consequences. Message persuasion for low-relevance subjects who elaborate on the consequences will not differ from that of low-relevance subjects who do not elaborate on the consequences. The prediction that increased elaboration will lead to increased persuasion, rather than decreased persuasion for high-relevance subjects assumes that further elaboration will generate more objective processing. The assumption that for a high-relevance individual, elaboration on a health-related appeal leads to favorable attitudes and increased compliance is consistent with the health-persuasion literature (Rosenstock, 1974; Rogers, 1983). One could argue, however, that increased elaboration on the consequences of one's behavior might lead to greater defensive processing. This would be detected by decreased message persuasion for the high-relevance subjects who further elaborated on the message compared to high-relevance subjects who did not. Confirmation of hypotheses 1-3 represents a substantial contribution to PMT and to theories of health-related information processing and persuasion. One criticism of PMT is that it fails to account for when and why people reject message recommendations (Witte, 1998). Thus, it fails to address that high-relevance people might engage in certain strategies that prevent or interfere with increased behavioral intentions, or that low-relevance people might respond 
differently. The current conceptual framework specifically accommodates diverse responses to fear appeals. Specifically, the contribution of this framework to PMT is to a) present theory that allows for different processing strategies among high-relevance consumers and between high and low-relevance consumers, and b) formally incorporate the role of elaboration in altering perceptions of severity and efficacy.

Hypotheses 1-3 are tested in the context of caffeine consumption in Study 1, and with olestra consumption in Study 2 using an elaboration enhancing method that can easily be applied within messages by health educators. Both studies contribute to prior theorizing on the defensive processing of personally relevant health messages by 1) demonstrating that elaboration on the consequences portion of the message in particular influences persuasion, 2) suggesting that elaboration on the consequences can be used as a mechanism to reduce defensive processing, and 3) specifying change appraisal as the process underlying message persuasion.

\section{Study 1: Method}

One hundred twenty-three (123) undergraduate students participated in the experiment in exchange for partial course credit. Each student was given a three-part questionnaire. The first part queried students on their level of caffeine consumption and prior beliefs about the association between caffeine and health problems. Students then read an article entitled "Health Bulletin: Spotlight on Caffeine" ${ }^{2}$, supposedly excerpted from one that had appeared in the New England Journal of Medicine (consistent with Liberman \& Chaiken, 1992). Subjects then filled out the questionnaire on their beliefs and intentions and were debriefed.

The article contained three sections: 1) What is caffeine found in?, 2) The Problem, and 3) The Solution (see Appendix A). The first part listed certain foods known to contain caffeine (e.g., coffee, tea, chocolate). The second section defined caffeine and informed students of the possible health consequences of high doses of caffeine consumption (e.g., insomnia, nervousness, 
anxiety, risk of cardiovascular disease). The final section provided recommendations for cutting back on caffeine consumption (e.g. "Try to gradually decrease your caffeine consumption.").

Elaboration. After reading the article, half of the subjects were instructed to elaborate on the consequences of caffeine consumption (elaboration-consequences condition). These subjects were given the instructions:

Think back to 'The Problem' mentioned in the article. Write a short essay indicating your thoughts on this problem. We are interested in your thoughts (for example, how you feel about the problem), not in what you remember from the article. Please keep in mind this is a personal essay, thus there are no right answers to this question.

To make sure that elaboration on the consequences and not elaboration on another part of the message influences persuasion, the other half of the students were given instructions to elaborate on the recommendations (elaboration-recommendations condition). These students were given the same instructions as above, with 'The Solution' substituted in the appropriate places. A manipulation check confirms that subjects wrote equal length essays regardless of condition; subjects in the elaboration-consequences condition wrote on average 40.8 words, while those in the elaboration-recommendations condition wrote $35.7(\mathrm{t}=1.57, \mathrm{p}>.10)$. Additionally, a second check confirmed that those students asked to write about the consequences (recommendations) wrote significantly more thoughts about the consequences (recommendations) than the other students (consequences: $\mathrm{M}=2.00$ vs. $\mathrm{M}=.95, \mathrm{~F}(1,121)=16.09$, $\mathrm{p}<.001$; recommendations: $\mathrm{M}=1.58$ vs. $\mathrm{M}=.54, \mathrm{~F}(1,121)=23.79, \mathrm{p}<.001]$.

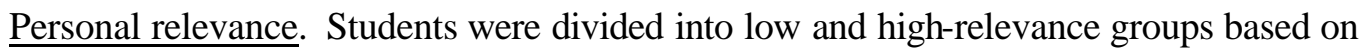
their responses to their level of caffeine consumption on the first part of the questionnaire. Sixtyone percent of the students who reported drinking less than two cups of caffeinated coffee or tea per day comprise the low-relevance group (mean for this group is .50 cups per day). ${ }^{3}$ The remaining high-relevance subjects reported drinking at least two cups per day (mean $=3.2$ cups per day, range 2-12 cups). A manipulation check queried subjects on how personally relevant the message was to them $(1=$ not, $7=$ extremely $)$. Results confirm that low-relevance subjects rated 
the message as less relevant $(\mathrm{M}=3.26)$ than the high-relevance subjects $[\mathrm{M}=3.95$, $\mathrm{F}(1,121)=5.94, \mathrm{p}<.01]$

Prior beliefs. To rule out the possibility that high-personal relevance subjects had stronger prior beliefs about the health risks of caffeine consumption, subjects were asked about their beliefs before reading the article. All students indicated their agreement on a seven point scale $(1=$ Strongly Disagree, $7=$ Strongly Agree $)$ with whether there is a strong association between caffeine and health problems (e.g., cardiovascular disease). No differences in prior beliefs were found across the four conditions (ps > .10).

To make sure that the initial measures of caffeine consumption and prior beliefs did not affect the nature of subjects' processing, a control group of twenty-five undergraduates was compared against the average level of processing across experimental conditions. These control subjects were not given the first part of the questionnaire on their usage and beliefs about caffeine consumption. To keep the procedure constant, particularly the time between reading the article and answering the questions, the control group was first given a filler task to write a short essay describing any advertisement for coffee or tea that they can remember. After finishing the essay, the students completed the survey. There were no differences between the control group and the average level of persuasion ( $M=4.2$ vs. $M=4.3, p>.10)$, recall $(M=7.6$ vs. $M=6.3, p>.10)$, change appraisal ( $M=40.7$ vs. $M=42.3, p>.10)$, perceived vulnerability ( $M=3.4$ vs. $M=3.7, p>$ $.10)$, or fear ( $M=2.8$ vs. $M=2.5, p>.10)$ in the experimental conditions. The control group was not used in any additional analysis.

\section{$\underline{\text { Measures }}$}

After they read the article on caffeine, subjects completed a questionnaire containing questions measuring persuasion, recall, change appraisal, perceived vulnerability and fear. All items are rated on a 7-point scale unless otherwise noted. 


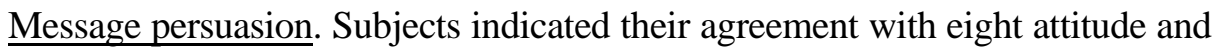
behavioral intention statements: Caffeine intake is strongly associated with health problems./It is important for a person to reduce caffeine consumption in order to avoid developing these health problems./The article was important in persuading me to reduce caffeine consumption./I should reduce my caffeine consumption./The article convinced me that too much caffeine poses health problems./I will reduce my caffeine consumption./ I will try to follow the recommendations in the article./I will try to reduce my caffeine intake. These eight items were measured on 7-point scales (1=Strongly Disagree, $7=$ Strongly Agree); they load on one factor with high reliability (Cronbach's ? =.92).

$\underline{\text { Recall. }}$ After the persuasion measure subjects were asked to write down everything they could recall reading in the article. Two independent coders (inter-rater reliability $=.95$ ), blind to the experimental conditions, allocated one point to each item recalled in each of three categories: 1) recall of what caffeine is found in, 2) recall of consequences and 3) recall of recommendations. Inconsistencies in the coding were reconciled by a third person. The consequences presented in the message may be threatening to a high-relevance individual by calling attention to the effects of his/her behavior. Likewise, the recommendations may be threatening by challenging the status quo of one's behavior. Therefore, recall of consequences and recall of recommendations were summed to provide one measure of Recall of Threatening Information. Recall of what caffeine is found in represents Recall of Non-Threatening Information.

Change appraisal. Students rated their perceptions of severity by indicating whether they thought the problems associated with caffeine consumption are serious ( $1=$ not at all serious, $7=$ extremely serious). Subjects indicated response efficacy by rating how much they agree or disagree that limiting caffeine consumption will avoid these health problems ( $1=$ strongly disagree, $7=$ strongly agree). They then rated self-efficacy by indicating how much they agree or disagree that the recommendations in The Solution are easy for them to do (1=strongly disagree, 7=strongly agree). Perceived severity, response efficacy and self-efficacy were combined to form 
change appraisal in a manner theoretically consistent with the current specification of PMT (see Footnote 1). This specification of PMT maintains that self-efficacy and response efficacy combine additively, and that efficacy (self and response) is multiplied by severity (Rogers \& Prentice-Dunn, 1997, Witte, 1998). Therefore, change appraisal is represented by the sum of response efficacy plus self-efficacy, multiplied by perceived severity ((Response efficacy + Selfefficacy)* Severity). Factor analysis confirms that perceived severity, response efficacy and selfefficacy load on one factor explaining $63.6 \%$ of the variance. Cronbach's $?=.71$.

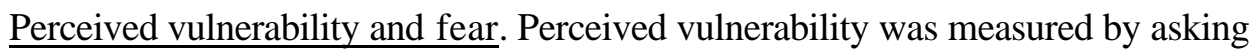
students whether caffeine related health problems are something that they need to worry about ( $1=\mathrm{I}$ do not need to worry, $7=\mathrm{I}$ do need to worry). Since PMT postulates that fear is sometimes aroused as a result of processing health-related messages, we also asked subjects whether they felt fearful while reading the article (1=Strongly disagree, $7=$ Strongly agree).

\section{Results}

$\underline{\text { Hypotheses Tests }}$

Hypotheses were examined according to an ANOVA design with elaboration as one factor, personal relevance as the second factor, and prior beliefs controlled for as a covariate. Beta values and significance levels are reported in analyses where prior belief is a significant covariate. Cell means and standard deviations for the four cells are presented in Table 1, columns 1-4. Column 5 reports the F-value and significance level for the Elaboration by Personal Relevance interaction for all variables. In all cases where the Elaboration by Personal Relevance interaction is significant, specific contrasts were tested; F-values and significance levels are reported in columns 6-9. The univariate effect size $\left(?^{2}\right)$ is reported; if $.01<?^{2}<.06$ then the effect is small, if $.06 ? ?^{2}<.14$ the effect is medium, and if $?^{2} ? .14$ the effect is large (Cohen, 1977; Goodstein, 1993). 
$\underline{\text { Hypothesis } 1 .}$ Kruglanski and Webster (1996) report that a reliance on early cues and a truncation of further exploration evidence seizing and freezing. Judgments under conditions of seizing and freezing are made based on information presented earlier in a sequence rather than later. In this study, the categories of information in the stimulus provide a sequence that can be used to detect seizing and freezing. All subjects regardless of condition saw the non-threatening information first (What is Caffeine Found In?), followed by the threatening information (The Problem and The Solution). Recall of threatening versus non-threatening message arguments can be used to detect seizing and freezing.

Hypothesis 1 predicts that in the absence of elaboration on the consequences, highrelevance people will freeze on the threatening information. If this is true, recall of the threatening information should be lower for high-relevance subjects than for low-relevance subjects in the elaboration-recommendations condition. If, as predicted in $\mathrm{H} 1$, high-relevance subjects unfreeze with increased elaboration, then recall of the threatening information should be lower for high-relevance subjects in the elaboration-recommendations condition than for highrelevance subjects in the elaboration-consequences condition. Information presented prior to the threatening part of the message (What is Caffeine Found In?) should be equally recalled.

Results of the recall measures support H1, indic ating a significant interaction of Elaboration by Personal Relevance on recall of the threatening information $(\mathrm{F}(1,116)=7.04, \mathrm{p}<$ $.01, ?^{2}=.06$; column 5 , Table 1$)$ and a main effect of elaboration $\left(\mathrm{F}(1,116)=7.95, \mathrm{p}<.01, ?^{2}\right.$ $=.06) .{ }^{4}$ Specifically, recall of the threatening information is 1) lower for high-relevance subjects in the elaboration-recommendations condition than low-relevance subjects in this condition $\left(\mathrm{M}=4.29\right.$ vs. $\mathrm{M}=6.42, \mathrm{~F}(1,58)=4.68, \mathrm{p}<.05, ?^{2}=.08$; column 9, Table 1), and 2) lower for hig $\mathrm{h}-$ relevance subjects in the elaboration-recommendations condition than high-relevance subjects in the elaboration-consequences condition $\left(\mathrm{M}=4.29\right.$ vs. $\mathrm{M}=8.10, \mathrm{~F}(1,43)=12.84, \mathrm{p}<.001, ?^{2}=.23$, column 6 , Table 1$).^{5}$ As predicted, results of recall of the non-threatening introductory 
information (What is Caffeine Found In?) show no main effect of Personal Relevance ( $p>.10)$ or interaction of Elaboration by Personal Relevance $(\mathrm{p}>.10)$ and a main effect of Elaboration $(\mathrm{F}(1,116)=4.03, \mathrm{p}<.05)$. Thus, results confirm $\mathrm{H} 1$.

\section{Table 1 about here}

Hypothesis 2. ANOVA on the change appraisal score indicates significant main effects of Elaboration $\left(\mathrm{F}(1,118)=3.95, \mathrm{p}<.05, ?^{2}=.03\right)$ and prior beliefs as a covariate $($ beta $=.36$ $\mathrm{t}(118)=4.37, \mathrm{p}<.001)$, and a significant interaction of Elaboration by Personal Relevance

$\left(\mathrm{F}(1,118)=4.32, \mathrm{p}<.02, ?^{2}=.04\right.$, column 5 , Table 1). As predicted, high-relevance subjects in the elaboration-consequences condition had higher change appraisal $(M=53.98)$ than high-relevance subjects in the elaboration-recommendations condition $\left(\mathrm{M}=36.71, \mathrm{~F}(1,45)=10.03, \mathrm{p}<.01, ?^{2}\right.$ $=.18$, column 6 , Table 1). There was no difference in change appraisal for low-relevance subjects $(\mathrm{p}>.10)$. Within the elaboration-consequences condition, high-relevance subjects had greater change appraisal than low-relevance subjects $\left(M=53.98\right.$ vs. $M=39.76, F(1,61)=7.13, p<.01, ?^{2}$ $=.11$, column 8 , Table 1 ). Note that Table 1 contains means, standard deviations, F-values and significance levels for the individual components of severity, self-efficacy and response efficacy. The basic pattern of results is consistent across these variables.

Baron and Kenny's (1986) procedure was used to test whether change appraisal mediates the effect of elaboration on message persuasion for high-relevance subjects. Baron and Kenny suggest three separate regressions: 1 ) the effect of elaboration on change appraisal (beta $=-.43$, $\mathrm{t}(43)=-3.17, \mathrm{p}<.01)$ the effect of elaboration on persuasion $($ beta $=-.36, \mathrm{t}(43)=-2.54, \mathrm{p}<.01)$, and 3) the effect of elaboration and change appraisal on persuasion (beta $=.71, \mathrm{t}(43)=6.18, \mathrm{p}<$ .001 for change appraisal; $\mathrm{p}>.10$ for elaboration). Significant effects of elaboration in the first two equations and a significant effect of change appraisal and a non-significant effect of elaboration in the third equation indicate full mediation. As suggested, the favorable influence of 
elaboration on persuasion for high-relevance subjects is mediated by perceptions of change appraisal. As is expected for low-relevance people, results of change appraisal regressed on elaboration fail to achieve significance $(\mathrm{p}>.10)$, thus negating the effect of change appraisal as a mediating process for low-relevance individuals.

Hypothesis 3. Results indicate a significant Elaboration by Personal Relevance interaction $\left(\mathrm{F}(1,116)=5.93, \mathrm{p}<.01 ; ?^{2}=.05 ;\right.$ column 5 , Table 1$)$ and covariate effect of prior beliefs (beta $=.50, \mathrm{t}(116)=6.40, \mathrm{p}<.001)$ on message persuasion. Analysis of specific contrasts confirms $\mathrm{H} 3$ that message persuasion is significantly higher in the elaboration-consequences condition (M=4.88) than the elaboration-recommendations condition for high-relevance subjects $\left(\mathrm{M}=3.73, \mathrm{~F}(1,43)=6.47, \mathrm{p}<.01, ?^{2}=.13\right)$. As predicted, message persuasion was not statistically different within the low-relevance conditions $(p>.10)$. See Table 1, columns 6 and 7.

In the presence of elaboration on the consequences, high-relevance subjects report greater message persuasion $(\mathrm{M}=4.88)$ compared to low-relevance subjects $(\mathrm{M}=4.01, \mathrm{~F}(1,60)=4.55, \mathrm{p}<$ $.05, ?^{2}=.07$; column 8 , Table 1). By contrast, in the absence of elaboration on the consequences, high-relevance subjects report decreased message persuasion $(\mathrm{M}=3.73)$ compared to lowrelevance subjects $\left(\mathrm{M}=4.50, \mathrm{~F}(1,57)=4.85, \mathrm{p}<.05, ?^{2}=.08 ;\right.$ column 9, Table 1$)$.

\section{$\underline{\text { Perceived Vulnerability and Fear }}$}

A main effect of personal relevance shows that high-relevance individuals reported greater perceived vulnerability than low-relevance individuals $(\mathrm{M}=4.14$ vs. $\mathrm{M}=3.25, \mathrm{~F}(1,119)=$ $\left.9.85, \mathrm{p}<.001, ?^{2}=.08\right)$. This is consistent with prior studies on defensive processing that showed that despite their defensive processing, high-relevance subjects reported greater vulnerability than low-relevance subjects did (e.g., Kunda, 1987). Perceived fear did not differ across the four conditions (ps > .10). 


\section{Discussion}

The goal of Study 1 was to experimentally test the conceptual model represented by the figure. Thus, a straightforward essay writing task was chosen as an elaboration-enhancing technique. However, this method of increasing elaboration is impractical for message design. In Study 2, described below, defensive processing was explored using a method to increase elaboration that could be manipulated within the message itself. In addition, this study uses a second test of seizing and freezing, an accuracy test, which corroborates the recall measure. Study

2 supports the conceptual model, and provides a practical way for health advertisers to increase elaboration, and subsequently increase message persuasion for at-risk consumers.

\section{Study 2: Method}

Ninety-two (92) graduate and undergraduate students earned $\$ 5.00$ to participate in the experiment, focusing on olestra, a fake-fat used in some low-fat snack products. Subjects first indicated their level of low-fat snack food consumption and prior beliefs about olestra. Students then read a two-page article containing information on 1) three personal case stories of the consequences of eating olestra, 2) FDA information affirming olestra's safety, 3) opinions from the medical community on the potential ill effects of olestra, and 4) recommendations for making an informed decision about eating products containing olestra. All information used in the stimulus came from the web sites listed on the second page of the article; see Appendix B for a sample article and the web addresses. After reading the article, students completed the questionnaire, were paid and debriefed.

Elaboration. One of the objectives of this study was to use a more practical elaboration manipulation: one that could be used in health advertising. To find an appropriate technique, a sample of brochures from a variety of organizations was first examined (e.g., American Liver Foundation, American Heart Association). The elaboration manipulation in this study was modeled after an existing health brochure (Condom Sense, 1998). 
In the previous study, subjects elaborated on either the consequences or the recommendations, and this manipulation was independent of the message. Results of this design confirm that elaborating on the consequences influences persuasion, but elaborating on the recommendations does not. In Study 2, the goal is to use an elaboration manipulation within the message, thus providing practical applicability. For this within message design, it was important to keep message content equivalent across conditions. The only way to do this is to set up a design whereby half the subjects are given an elaboration enhancing technique, and the other half are given the same factual content without the elaboration enhancing technique. With this design, subjects in all conditions are given the same information regarding consequences, however, some are elaborating on the consequences while others are not. For completeness of design, two conditions are also created wherein subjects are given the same information regarding recommendations, with half the subjects elaborating on the recommendations and the others not. This results in a 2 Elaboration on Consequences (present, absent) by 2 Elaboration on Recommendations (present, absent) by 2 Personal Relevance (low, high) design. Prior research and the results of Study 1 show that elaboration on the consequences, rather than the recommendations, drives message persuasion. Therefore, the hypothesized effects on the Elaboration on Consequences by Personal Relevance interaction are expected. Increased elaboration on the recommendations should yield no significant effects.

For both elaboration on the consequences, and elaboration on the recommendations, subjects in the elaboration-present condition were given explicit directions to read the information plus a line drawing encouraging elaboration on message content. The directions and line drawings were removed in the elaboration-absent conditions. All other information was held constant and located in the same position in the ad. To keep the elaboration-absent condition realistic looking, a meaningless graphic design filled the empty space. See Appendix B for sample stimuli.

Results of a thought-listing task ("Write down the thoughts that crossed your mind as you read the article.") confirm that this technique did successfully manipulate elaboration of the 
consequences and elaboration of the recommendations. Two independent coders, with an interrater reliability of .93 (discrepancies reconciled through discussion) categorized each thought into one of three categories. These categories were 1) thoughts about the consequences (e.g., "Worried that olestra may affect my calcium levels - bone density."), 2) thoughts about the recommendations (e.g., "Would like to hear my personal doctor's view.”), and 3) thoughts unrelated to either of these (e.g., "I wonder what olestra tastes like."). As anticipated, subjects in the elaboration on the consequences - present condition had significantly more thoughts about the consequences $(\mathrm{M}=3.63)$ than subjects in the elaboration on the consequences - absent condition $(\mathrm{M}=2.78, \mathrm{~F}(1,90)=4.02, \mathrm{p}<.05)$. Results also confirm that subjects in the elaboration on the recommendations - present condition had significantly more thoughts about the recommendations $(M=1.75)$ than subjects in the elaboration on the recommendations - absent condition $(M=1.03$, $\mathrm{F}(1,90)=4.30, \mathrm{p}<.05)$.

There was no theoretical reason to expect differences in persuasion across elaboration on the recommendation - present versus absent conditions. As expected, results of an ANOVA reveal an insignificant three-way interaction of Personal Relevance by Elaboration on Consequences by Elaboration on Recommendations ( $\mathrm{F}<1$ ), insignificant two-way interactions of Personal Relevance by Elaboration on Recommendations ( $\mathrm{F}=1.18, \mathrm{p}=.28)$ and Elaboration on Consequences by Elaboration on Recommendations ( $\mathrm{F}<1$ ), and an insignificant main effect of Elaboration on Recommendations $(\mathrm{F}<1)$. Thus, the two elaboration on the recommendation (present and absent) conditions were collapsed. All remaining analyses were conducted only on personal relevance and elaboration on the consequences, and all subsequent references to elaboration-present versus elaboration-absent refer only to elaboration on the consequences.

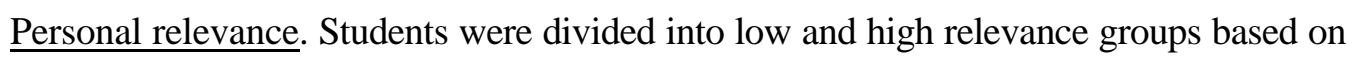
their level of low-fat snack food consumption. Each subject rated the quantity of low-fat snack foods that they consume, on average, per week on an 11-point scale $(0=$ None at all, $10=\mathrm{A}$ tremendous amount). As close to a median split as possible, given the distribution of the 
responses, was used to break subjects into low versus high-relevance groups. Forty-two percent of respondents fell into the low-relevance groups (mean=.44, range $=0-1$ ), and the remaining $58 \%$ fell into the high-relevance group (mean=3.7, range=2-9). A manipulation check queried subjects on how personally relevant the message was to them (1=not, $7=$ extremely). Results confirm that low-relevance subjects rated the message as less relevant $(M=4.00)$ than the high-relevance subjects did $[\mathrm{M}=5.06, \mathrm{~F}(1,90)=6.43, \mathrm{p}<.01]$.

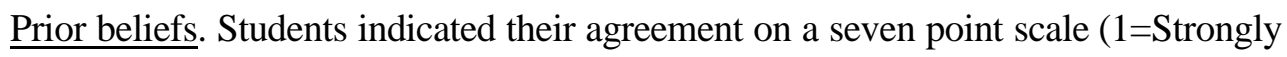
Disagree, 7=Strongly Agree) with whether there is a strong association between olestra and health problems. No differences in prior beliefs were found across the four conditions (Fs < 1). As in Study 1, a control group of fifteen graduate students was not asked the initial measures of olestra consumption and prior beliefs to make sure that these measures did not affect the nature of subjects' processing. As there were no differences between the control group and the average level of persuasion ( $\mathrm{M}=4.3$ vs. $\mathrm{M}=4.8, \mathrm{p}>.10)$, recall ( $\mathrm{M}=4.0$ vs. $\mathrm{M}=3.2, \mathrm{p}>.10)$, change appraisal ( $M=33.7$ vs. $M=44.1, p>.10)$, perceived vulnerability ( $M=3.8$ vs. $M=3.7, p>.10)$, or fear $(M=3.6$ vs. $M=3.7, p>10$ ) in the experimental conditions, the control group was not used in further analysis.

$\underline{\text { Measures }}$

Message persuasion. Subjects indicated their agreement with five attitude and behavioral intention statements: Olestra is strongly associated with health problems./It is important for a person to reduce olestra consumption in order to avoid developing these health problems./I will not eat foods made with olestra./ I will try to follow the recommendations in the article./I will think twice before eating food made with olestra ( $1=$ Strongly Disagree, $7=$ Strongly Agree). These five items load on one factor with high reliability (Cronbach's $?=.80$ ).

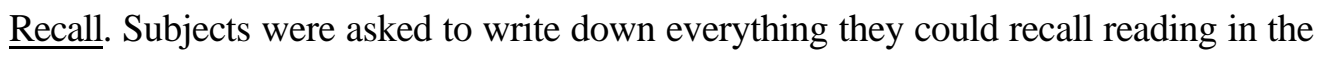
article. Each item was allocated one point in each of three categories: 1) recall of the non- 
threatening information (What the FDA Says), 2) recall of the threatening information (What the Medical Community Says) and 3) recall of recommendations. ${ }^{6}$ This recall measure was coded by the same two people who coded the thought-listing elaboration manipulation check; inter-rater reliability on recall was .96 with discrepancies resolved through discussion.

Accuracy test. Students were given an accuracy test to check for evidence of seizing and freezing. Participants were presented with a list of statements, and told to circle either Yes or No, depending on whether they thought the statement was in the article: Yes = yes, the statement was in the article, No $=$ no, the statement was not in the article. Percent correct was calculated for two groups of statements, Accuracy of the Non-threatening information (What the FDA Says) and Accuracy of the Threatening information (What the Medical Community Says). To indicate seizing and freezing, high-relevance subjects should have equal accuracy of the non-threatening information regardless of elaboration condition. This was represented by subjects' percent correct on three statements that were in the article: The FDA reaffirmed the safety of Olestra./Studies show that people who eat Olestra have the same amount of digestive effects as people who eat full-fat snacks./There is no direct evidence that carotenoids are responsible for lower disease risk. By contrast high-relevance subjects who unfroze on the message (elaboration-present condition) should have a greater percent correct of the threatening information, represented by six statements that were actually present in the article and three statements that were not. The six statements actually in the article, followed by the three that were not are: Olestra passes through the body undigested./Eating a small bag of Olestra chips can reduce beta carotene by $60 \%$./Vitamin D is involved in calcium metabolism./Vitamin E protects against cancer and heart disease./Olestra robs the body of important vitamins./Vitamin $\mathrm{K}$ is important in blood clotting./Olestra causes blurry vision./Vitamin B is important for stress reduction./Olestra robs the body of Vitamin C.

Change appraisal. Students rated their perceptions of severity by indicating whether they thought the problems associated with olestra consumption are serious ( $1=$ not at all, $7=$ extremely). The response efficacy scale measured subjects' agreement that limiting olestra consumption will 
avoid these health problems (1=strongly disagree, $7=$ strongly agree). Self-efficacy was measured by asking subjects to rate their agreement with a statement that they can reduce their own olestra intake to reduce their own risk of getting these heath problems ( $1=$ strongly disagree, $7=$ strongly agree). As is Study 1, these three items were combined in accordance with PMT. Change appraisal is represented by the sum of response efficacy plus self-efficacy, multiplied by perceived severity. Factor analysis confirms that perceived severity, response efficacy and selfefficacy load on one factor explaining $70.4 \%$ of the variance. Cronbach's $?=.78$.

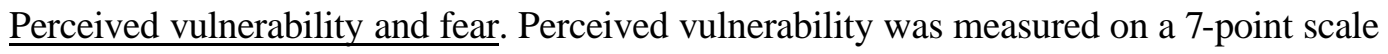
by asking students whether olestra related health problems could happen to them (1=cannot happen to me, 7=can happen to me). Perceived fear was measured by asking subjects to indicate how fearful they felt while reading the article (1=Strongly disagree, $7=$ Strongly agree).

\section{Results}

\section{$\underline{\text { Hypotheses Tests }}$}

Results of this study support the conceptual framework illustrated in the Figure and are consistent with Study 1. Cell means and standard deviations for the four cells are presented in Table 2, columns 1-4. Column 5 reports the F-value and significance level for the Elaboration by Personal Relevance interaction for all variables. In all cases where the Elaboration by Personal Relevance interaction is significant, specific contrasts were tested; F-values and significance levels are reported in columns 6-9.

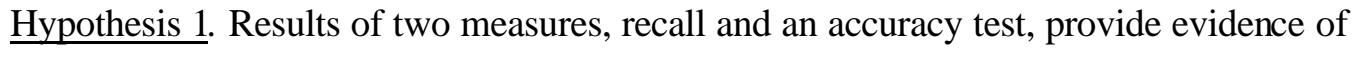
seizing and freezing. To evidence seizing and freezing, we would expect equal recall of, and accuracy regarding the non-threatening information, in this case information supporting the FDA approval of olestra. However, we should expect high-relevance subjects who elaborated to have greater recall and accuracy of the threatening information, in this case information from the medical community, than high-relevance consumers who did not elaborate. 
Results of the recall measures support H1. Results reveal a significant interaction of Elaboration by Personal Relevance on recall of the threatening information $(F(1,87)=7.95, p<.01$, $?^{2}=.08$, column 5 , Table 2). Analyses of specific contrasts reveals that recall of the threatening information is lower for high-relevance subjects in the elaboration-absent condition ( $M=2.67)$ than high-relevance subjects in the elaboration-present condition $(\mathrm{M}=4.39, \mathrm{~F}(1,51)=6.15, \mathrm{p}<.01$, $?^{2}=.11$, column 6, Table 2). Additionally, high-relevance subjects in the elaboration-present condition $(\mathrm{M}=4.39)$ recalled more threatening information than low-relevance subjects in this condition $\left(\mathrm{M}=2.56, \mathrm{~F}(1,49)=7.06, \mathrm{p}<.01, ?^{2}=.13\right.$, column 8 , Table 2).

As expected, there were no main effects or interaction effect of Elaboration and Personal Relevance on recall of the non-threatening information (What the FDA Says; Fs $<1$ ). The effect of prior beliefs is significant $($ beta $=-.21, \mathrm{t}(87)=-2.01, \mathrm{p}<.05)$.

\section{Table 2 about here}

Results of the accuracy test also provide evidence of seizing and freezing. High-relevant consumers should score equally on the accuracy test for the non-threatening information (What the FDA Says). Results confirm that the average percent correct on the Accuracy-Nonthreatening measure for high-rele vant subjects was the same regardless of elaboration condition $(\mathrm{M}=.62$ vs. $\mathrm{M}=.63, \mathrm{p}>.10)$.

If high-relevant consumers in the elaboration-present condition "unfroze", they should have greater accuracy on the threatening information than high-relevant consumers in the elaboration-absent condition. Results of the accuracy test on the threatening material unmasked an interesting task effect. At first, results of the Accuracy-Threatening measure indicated that high-relevant subjects in the elaboration-absent condition $(M=.77)$ had an equal accuracy score to those in the elaboration-present condition $(\mathrm{M}=.75, \mathrm{p}>.10)$. However, further analysis revealed an aggregation bias on this measure; in fact, it was only those statements that were actually present 
in the article (correct answer was Yes) for which high-relevant subjects in the elaboration-absent condition ( $M=.77)$ had equal accuracy to those in the elaboration-present condition $(M=.69$, p>.10). For those statements that were not present in the article (correct answer was No), accuracy significantly increased from the elaboration-absent condition $(M=.77)$ to the elaboration-present condition $(\mathrm{M}=.88, \mathrm{~F}(1,51)=2.96, \mathrm{p}<.05)$. It appears that high-relevance subjects who were defensively processing, and froze on the message simply responded Yes to all statements. However, high-relevance subjects in the elaboration-present condition, who unfroze on the message, were able to correctly distinguish the statements that were in the article (Yes) from those that were not (No).

Hypothesis 2. Results confirm $\mathrm{H} 2$ with a significant interaction between Elaboration and Personal Relevance $\left(\mathrm{F}(1,84)=4.93, \mathrm{p}<.05, ?^{2}=.06\right.$, column 5, Table 2$)$ and a main effect of Personal Relevance $\left(\mathrm{F}(1,84)=7.09, \mathrm{p}<.01, ?^{2}=.08\right)$ on change appraisal. The interaction is directionally consistent but either marginally significant or not significant for the individual components of change appraisal.

Consistent with $\mathrm{H} 2$, high-relevance subjects in the elaboration-present condition had higher change appraisal $(M=57.12)$ than high-relevance subjects in the elaboration-absent condition $\left(\mathrm{M}=42.88, \mathrm{~F}(1,48)=5.36, \mathrm{p}<.01, ?^{2}=.10\right.$, column 6 , Table 2$)$. There was no difference in change appraisal for low-relevance subjects ( $\mathrm{p}>.10$; column 7, Table 2). Within the elaborationpresent condition, high-relevance subjects had greater change appraisal than low-relevance subjects $\left(\mathrm{M}=57.12\right.$ vs. $\mathrm{M}=32.96, \mathrm{~F}(1,48)=14.44, \mathrm{p}<.001, ?^{2}=.23$; column 8, Table 2).

The same procedure described in Study 1 was used in this study to test whether change appraisal mediates the effect of elaboration on message persuasion for high-relevance subjects. Results of the three regressions indicate full mediation: 1) the effect of elaboration on change appraisal (beta $=-.32, \mathrm{t}(48)=2.32, \mathrm{p}<.05), 2)$ the effect of elaboration on persuasion (beta=-.32, $\mathrm{t}(48)=2.39, \mathrm{p}<.05$ ), and 3 ) the effect of elaboration and change appraisal on persuasion (beta=.27, 
$\mathrm{t}(48)=1.96, \mathrm{p}=.05$ for change appraisal; beta $=-.23, \mathrm{t}(48)=1.71, \mathrm{p}<.10$ for elaboration). Significant effects of elaboration in the first two equations, and significance of change appraisal and an insignificant effect of elaboration in the third equation indicate full mediation. Similar to Study 1, for low-relevance people, results of change appraisal regressed on elaboration fail to achieve significance ( $p>.10)$.

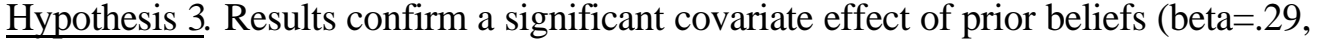
$\mathrm{t}(87)=2.89, \mathrm{p}<.01)$ and a significant interaction between Elaboration and Personal Relevance $\left(\mathrm{F}(1,87)=3.89, \mathrm{p}<.05, ?^{2}=.04\right.$; column 5 , Table 2$)$ on message persuasion as predicted by $\mathrm{H} 3$. Consistent with the hypothesis, persuasion is significantly higher in the elaboration-present condition ( $M=5.35)$ than the elaboration-absent condition for high-relevance subjects $(M=4.70$, $\left.\mathrm{F}(1,51)=4.07, \mathrm{p}<.05, ?^{2}=.07\right)$. Message persuasion was not statistically different within the lowrelevance conditions ( $p>.10)$. See Table 2, columns 6 and 7. In the presence of elaboration on the consequences, high-relevance subjects report greater message persuasion $(\mathrm{M}=5.35)$ compared to low-relevance subjects $\left(\mathrm{M}=4.33, \mathrm{~F}(1,49)=8.97, \mathrm{p}<.01, ?^{2}=.16\right.$; column 8 , Table 2$)$.

\section{$\underline{\text { Perceived Vulnerability and Fear }}$}

As expected, high-relevance individuals felt more vulnerable than low-relevance individuals ( $\mathrm{M}=4.71$ vs. $\left.\mathrm{M}=3.87, \mathrm{~F}(1,87)=5.17, \mathrm{p}<.05, ?^{2}=.06\right)$. Additionally, a main effect of fear indicates that high-relevance students felt more fearful than low-relevance subjects $(M=4.17$ vs. $\mathrm{M}=3.15, \mathrm{~F}\left(1,88=6.16, \mathrm{p}<.05, ?^{2}=.05\right)$. In Study 1 , perceived fear did not differ across the four conditions. This inconsistency will be discussed in the Discussion section.

\section{Discussion}

Previous studies have found that people process personally relevant health messages in a biased manner, leading to decreased persuasion and unfavorable judgments. This is unf ortunate, 
as health messages advocating behavioral change are most applicable to those for whom the behavior is personally relevant. This paper examines the role of elaboration as a mechanism to encourage less biased processing of personally relevant health appeals. By decreasing biased processing, we can hope to increase persuasion and compliance for those who are most at-risk of adverse health consequences.

Results of two studies, one on caffeine consumption (Study 1) and one on olestra consumption (Study 2) support the conceptual framework illustrated in the Figure. Highrelevance consumers who do not elaborate on the consequences freeze on the threatening portion of the message; increased elaboration on the consequences will "unfreeze" message processing, as evidenced by recall measures in both studies, and an accuracy test in Study 2. Unfreezing on the threatening information increases change appraisal (severity, response efficacy and selfefficacy) which leads to greater message persuasion. A series of mediation tests in Study 1 and Study 2 confirm that change appraisal mediates the effect of elaboration on message persuasion for high-relevance individuals. Results support the theorizing that 1) increased elaboration on the consequences can reduce defensive processing for high-relevance consumers, 2) it is elaboration on the consequences, rather than the recommendations that influences persuasion, and 3) change appraisal is the process underlying message persuasion.

Results of the current study complement findings from a study of the precaution adoption process model (PAPM; Weinstein, Lyon, Sandman and Cuite 1998). The PAPM, like all stage of change models, is based on the premise that behavioral change occurs in stages or phases, and that movement between stages depends on a set of factors unique to each stage. The specific number and name of each stage differs depending on the model. PAPM defines 7 stages: 1) unaware of the health action, 2) aware but not personally engaged, 3) engaged and trying to decide what to do, 4) decided not to act, 5) decided to act but not yet having acted, 6) acting, and 7) maintaining the new health behavior (Weinstein et al. 1998). Weinstein and colleagues tested the effects of different informational videos on stage movement among "undecideds" (stage 3). 
They found that the video containing information about the risk of home radon levels ("consequences") was more effective than the video containing information on how to test for radon ("recommendations") in getting people to progress onward from stage 3. This basic finding mirrors our theorizing that elaboration on the consequences rather than the recommendations drives persuasion. Unfortunately, Weinstein et al. do not measure elaboration or any other process indicators; and, while it is reasonable to assume that our high-relevance respondents were in stage 3, we do not measure stage classification or transition. Together however, the current study and Weinstein's study complement each other by identifying both the process and the stage movement that can arise from informational health appeals.

What is particularly intriguing about the Weinstein study is the implication for future research. Both the PAPM and the Transtheoretical Model (TM; Prochaska and DiClemente 1982, 1983) suggest that different processing biases exist for people with different levels of perceived vulnerability. For example, Prochaska, Norcross and DiClemente (1994) discovered self-serving denials such as positive self-illusions and rationalizations enable precontemplators to avoid seeing their problems. It would be interesting to explore seizing and freezing tendencies across stages. For example, does defensive processing decrease linearly across stages, or is there a point of inflection around the action stage, after which defensive processing increases - only the content one freezes on is different?

The effect sizes reported in this study ranged from .04 to .23 , which represents effects of small to large magnitude; if $.01<?^{2}<.06$ then the effect is small, if $.06 ? ?^{2}<.14$ the effect is medium, and if $?^{2} ? .14$ the effect is large (Cohen, 1977, Goodstein, 1993). Small effect sizes in health-persuasion may still signal meaningful progress in theory development and be a signal of a healthy and productive area of research (Fern \& Monroe, 1996). Since the effect sizes range from small to large, the results reported in this paper indeed provide meaningful progress in theory development for health-persuasion. 
There were no main effects or interaction effects of elaboration and personal relevance on perceived fear in Study 1, and a main effect of personal relevance on perceived fear in Study 2. In fact, the role of fear in message persuasion is still uncertain. We are still in need of a unifying fearpersuasion paradigm that accommodates extant data and is capable of providing specific guidelines for using fear as a persuasive advertising strategy. According to PMT, fear is a byproduct of the message that may or may not be aroused during message processing (Rogers, 1975, 1983). Notice that perceived fear is not part of "protection motivation." We studied seizing and freezing on information about caffeine and olestra consumption. Exploring seizing and freezing tendencies in health domains that might be more fear-inspiring (i.e., across level of fear) might help reconcile some of the existing uncertainties in the fear-persuasion literature.

Although as hypothesized message persuasion is not significantly different across elaboration conditions for low-relevance people (ps>.10), a look at the cell means in both studies suggests that message persuasion is directionally greater when low-relevance subjects are not elaborating on the consequences (Study 1: $\mathrm{M}=4.01$ vs. $\mathrm{M}=4.50$; Study 2: $\mathrm{M}=4.33$ vs. $\mathrm{M}=4.90$ ). We also know that change appraisal is not the process through which low-relevance subjects are persuaded. Since low-relevance consumers are also at times targeted with health appeals (for example, the benefits of self-breast exams for low-risk younger women), it is interesting to speculate on how the elaboration-persuasion linkage operates for them. It is possible that since the consequences are not probable or immediate for this group, increased elaboration on the consequences is simply an unpleasant task that leads to negative associations or even source derogation. Perhaps using a positive appeal rather than a traditional negative appeal would be more effective. Future research might extend this study to explore the processes underlying persuasion specifically for low-rele vance individuals.

This study relied on recall measures and an accuracy check (study 2) for evidence of seizing and freezing. Replication of this experiment with more sophisticated technology (e.g., tachistoscope) or with other process tracing methods might provide additional indicators of 
seizing and freezing. This paper suggests elaboration as one way to undo freezing on the threatening information. Further investigation of ways to accomplish unfreezing, perhaps for nonthreatening messages, would provide an interesting extension of this paper. 


\section{Footnotes}

1. PMT initially predicted that the components of the model would combine multiplicatively. This rule was rejected because PMT research failed to confirm the higher order interaction effects. Rogers then suggested, and subsequently discarded, an additive rule so that even if one of the predictor variables were zero, this could be compensated for by high levels of the other two variables. To date, studies provide mixed support for the combinatorial rule applicable to the effects of severity, vulnerability, self-efficacy and response efficacy (cf. Duval \& Mulilus, 1999 for a review of the combinatorial rules). Some studies support the multiplicative rule (Rippetoe \& Rogers, 1987), others an additive rule (Maddux \& Rogers, 1983), while other studies support neither a multiplicative nor an additive rule (Mulilus \& Lippa, 1990). Therefore, for the current study, the combinatorial rule recently specified by Rogers in a summary chapter on PMT was used (Rogers \& Prentice-Dunn, 1997). This combinatorial rule maintains that self-efficacy and response efficacy combine additively, and efficacy (response and self) is multiplied by severity and/or vulnerability (Rogers \& Prentice-Dunn, 1997, see also Witte, 1998).

2. The information in the article comes from two papers on caffeine use: Vener and Krupka (1982) and Jacobson and Bouher (1991).

3. Although other food and beverages may contain caffeine, it is present to a much lesser extent in these substances (Vener \& Krukpa, 1982). Additionally, this breakdown of low and high relevance groups was as close to a median split as possible given the distribution of responses. 4. Differences in degrees of freedom reflect missing data.

5. Note that the pattern of results for recall of the Threatening information holds for both recall of consequences and recall of recommendations. Specifically, recall is 1) lower for high-relevance subjects in the elaboration-recommendations condition than low-relevance subjects in this condition (for recall of consequences: $\mathrm{M}=2.50$ vs. $\mathrm{M}=3.83, \mathrm{~F}(1,58)=4.63, \mathrm{p}<.02, ?^{2}=.07$; for recall of recommendations: $\mathrm{M}=1.79$ vs. $\left.\mathrm{M}=2.58, \mathrm{~F}(1,58)=2.10, \mathrm{p}<.10, ?^{2}=.04\right)$, and 2) lower 
for high-relevance subjects in the elaboration-recommendations condition than high-relevance subjects in the elaboration-consequences condition (for recall of consequences: $\mathrm{M}=2.50 \mathrm{vs.} \mathrm{M}=$ 4.86, $\mathrm{F}(1,43)=11.03, \mathrm{p}<.001, ?^{2}=.20$; for recall of recommendations: $\mathrm{M}=1.79$ vs. $\mathrm{M}=3.24$, $\left.\mathrm{F}(1,43)=5.15, \mathrm{p}<.01, ?^{2}=.11\right)$. Thus, results support the theorizing that high-relevance people freeze on the consequences portion of the message, that freezing truncates further processing of the message, and that increased elaboration on the consequences "undoes" message freezing. 6. During the debriefing process, students in the elaboration-absent condition mentioned that they did not know where to start reading, the first column or the second. Therefore, items recalled regarding the three personal stories in the first column were not considered in the evidence of seizing and freezing. 


\section{References}

Bandura, A. (1986). Self-efficacy: toward a unifying theory of behavioral change. Psychological Review, 84, 191-215.

Baron, R. M. and D. A. Kenny (1986). The moderator-mediator variable distinction in social psychological research: conceptual, strategic, and statistical considerations. Journal of Personality and Social Psychology, 51 (6), 1173-1182.

Cohen, J. (1977). Statistical Power for the Behavioral Sciences, New York: Academic Press.

Condom Sense (1998). Newsletter prepared in conjunction with Student Health Service, University of North Carolina at Chapel Hill.

Donohew, L., E. Lorch, and P. Palmgreen (1991). Sensation seeking and targeting of televised anti-drug PSAs. In L. Donohew, H. E. Sypher and W. J. Bukoski, (Eds.), Persuasive Communication and Drug Abuse Prevention (pp. 209-26). Hillsdale, NJ: Lawrence Erlbaum Associates.

Duval, T. S. and J.-P. Mulilus (1999). A person-relative-to-event (PrE) approach to negative threat appeals and earthquake preparedness: a field study. Journal of Applied Social Psychology, 29 (3), 495-516.

Eagly, A. H., and S. Chaiken (1993). The Psychology of Attitudes, Orlando, FL: Harcourt Brace Jovanovich, Inc.

Fern, E. F. and K. B. Monroe (1996). Effect-size estimates: issues and problems in interpretation. Journal of Consumer Research, 23 (2), 89-105.

Goodstein, R. C. (1993). Category-based applications and extensions in advertising: motivating more extensive ad processing. Journal of Consumer Research, 20 (1), 87-99.

Hovland, C. I., I. L. Janis and H. H. Kelley (1953). Communication and Persuasion: Psychological Studies of Obvious Change, New Haven, CT: Yale University Press. 
Jacobson, B. H. and B. J. Bouher (1991). Caffeine consumption by selected demographic variables. Health Values, 15 (4), 49-55.

Jemmott, J. B. III, P. H. Ditto and R. T. Croyle (1986). Judging health status: effects of perceived prevalence and personal relevance. Journal of Personality and Social Psychology, 50 (5), 899-905.

Keller, P. A. and L. G. Block (1996). Increasing the persuasiveness of fear appeals: the effect of arousal and elaboration. Journal of Consumer Research, 22, 448-459.

Kruglanski, A. W. and D. M. Webster (1996). Motivated closing of the mind: 'seizing' and ‘freezing'. Psychological Review, 103 (2) 263-283.

Kunda, Z. (1987). Motivated inference: self-serving generation and evaluation of causal theories. Journal of Personality and Social Psychology, 53 (4), 636-647.

Kunda, Z. (1990). The case for motivated reasoning. Psychological Bulletin, 108 (3), 480-498.

Leventhal, H. (1970). Findings and theory in the study of fear communications. In L. Berkowitz (Ed.), Advances in Experimental Social Psychology (Vol. 5, pp. 119-185) New York: Academic Press.

Liberman, A. and S. Chaiken (1992). Defensive processing of personally relevant health messages. Personality and Social Psychology Bulletin, 18 (6), 669-679.

Maddux, J. E. and R. W. Rogers (1983). Protection motivation and self-efficacy: a revised theory of fear appeals and attitude change. Journal of Experimental Social Psychology, 19, 469-479.

Mulilus, J-P, \& Lippa, R.A. (1990). Behavioral change in earthquake preparedness due to negative threat appeal: A test of protection motivation theory. Journal of Applied Social Psychology, 20, 619-638.

Petty, R. E. and J. T. Cacioppo (1986). The elaboration likelihood model of persuasion. In L. Berkowitz (Ed.), Advances in Experimental Social Psychology (Vol. 19, pp. 123-205), Orlando, FL: Academic Press. 
Prochaska, J. O., \& DiClemente, C. C. (1982). Transtheoretical therapy: toward a more integrative model of change, Psychotherapy: Theory, Research and Practice, 19 (3), 276 88.

Prochaska, J. O., \& DiClemente, C. C. (1983). Stages and processes of self-change of smoking: toward an integrative model of change, Journal of Consulting and Clinical Psychology, 51 (3), $390-95$.

Prochaska, J. O., J. C. Norcross and C. C. DiClemente (1994). Changing for Good, William Morrow and Company, Inc.: New York.

Rippetoe, P.A., \& Rogers, R. W. (1987). Effects of components of protection-motivation theory on adaptive and maladaptive coping with a health threat. Journal of Personality and Social Psychology, 52, 596 - 604.

Rogers, R. W. (1975). A protection motivation theory of fear appeals and attitude change. Journal of Psychology, 91, 93 - 114.

Rogers, R. W. (1983). Cognitive and physiological processes in fear appeals and attitude change: a revised theory of protection motivation. In J. T. Cacioppo and R. E. Petty (Eds.) Social Psychophysiology (pp. 153-176), New York: Guilford Press.

Rogers, R. W. and S. Prentice-Dunn (1997). Protection motivation theory. In D. S. Gochman (Ed.), Handbook of Health Behavior Research I: Personal and Social Determinants (pp. 113-132), New York, NY: Plenum Press.

Rosenstock, I. M. (1974). Historical origins of the health belief model. In M. H. Becker (Ed.), The Health Belief Model and Personal Behavior (pp. 1-8), Charles B. Slack, Inc., New Jersey.

Stuteville, J. R. (1970). Psychic defenses against high fear appeals: A key marketing variable. Journal of Marketing, 34 (April), 39-45.

Vener, A. M. and L. R. Krupka (1982). Caffeine use and young adult women. Journal of Drug Education, 12 (3), 273-283. 
Weinstein, Neil D., Judith E. Lyon, Peter M. Sandman and Cara L. Cuite (1998). Experimental evidence for stages of health behavior change: the precaution adoption process model applied to home radon testing. Health Psychology, 17 (5), 445-53.

Witte, K. (1998). Fear as motivator, fear as inhibitor: using the extended parallel process model to explain fear appeal successes and failures. In P. A. Andersen and L. K. Guerrero (Eds.), Handbook of Communication and Emotion: Research, Theory, Applications, and Contexts (pp. 423-450), Academic Press: San Diego. 
Table 1 
Insert Table 2 
Appendix A

\section{HEALTH BULLETIN: Spotlight on CAFFEINE}

The following is excerpted from an article that appeared in the New England Journal of Medicine this past month.

\section{WHAT IS CAFFEINE FOUND IN?}

Caffeine, an ingredient in numerous beverages, foods, and proprietary drugs, is one of the few drugs that presents itself regularly in our food supply to people of all ages. Although most commonly associated with coffee, caffeine or similar xanthine derivatives may be present in tea, carbonated soft drinks, chocolates, soft candies, baked goods, frozen dairy products, gelatins, puddings, and over 1000 over the counter drugs (such as Anacin, Cope, Midol, Excedrin, Dexatrim and Vivarin).

\section{THE PROBLEM:}

Caffeine, one of three similar xanthine derivatives, is a powerful nervous system stimulant that rapidly empties from the stomach, is absorbed from the gastrointestinal tract, and can affect the cardiac muscle, kidneys, and certain glands. Caffeine has been shown to produce trembling, chronic muscle tension, insomnia, nervousness, irritability, and anxiety. High doses of caffeine may cause nausea, diarrhea, and peptic ulcers. Recent evidence suggests that caffeine's effect on the cardiovascular system could contribute to a greater risk of cardiovascular disease, like coronary heart disease or stroke, and elevated cholesterol levels.

\section{THE SOLUTION:}

The solution is easy: cut back on caffeine ingestion. Think over your daily routine. Do you have caffeine for breakfast? For lunch? After dinner? How many total cups of caffe ine do you drink on a daily basis? Could you forgo any of these? Try to gradually decrease your caffeine consumption. If you consume high quantities of caffeine, you might experience withdrawal symptoms. These symptoms mimic those of an anxiety state and include instability, inability to work effectively, nervousness, lethargy and headaches. These symptoms may appear 12 to 16 hours after the last dosage with associated headaches lasting from 1 to 7 days. But, don't despair, these symptoms will eventually disappear. 
Insert appendix B, page 1 
Insert appendix B, page 2 


\section{Figure}

Conceptual Illustration of the Effects of Elaboration on Message Persuasion

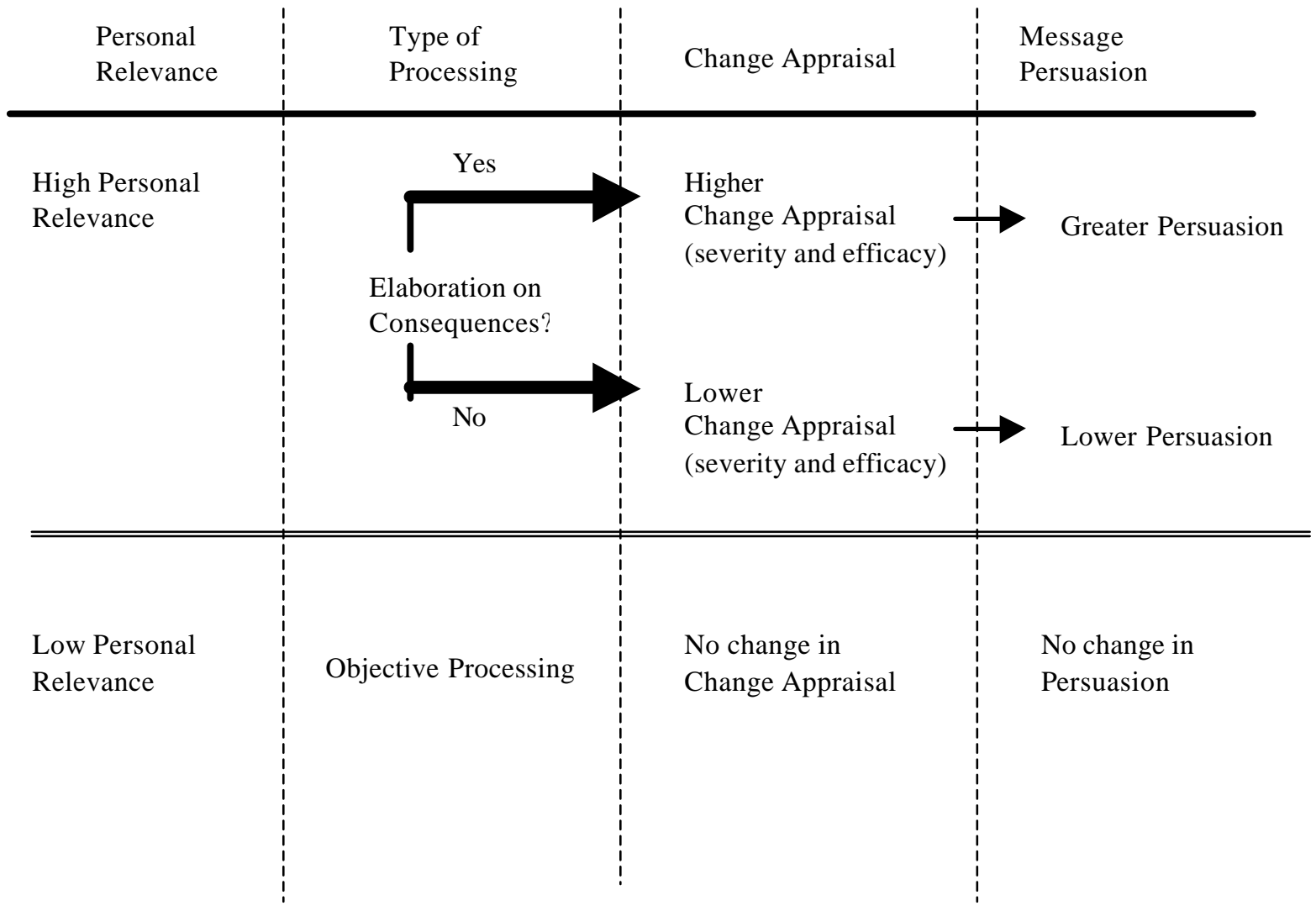

